\title{
Site Scientific Mission Plan for the Southern Great Plains CART Site
}

\author{
July-December 1999
}

Prepared for the U.S. Department of Energy under Contract W-31-109-Eng-38

Site Program Manager Office Environmental Research Division Argonne National Laboratory Argonne, IL 60439 


\section{DISCLAIMER}

This report was prepared as an account of work sponsored by an agency of the United States Government. Neither the United States Government nor an agency thereof, nor any of their employees, makes any warranty, express or implied, or assumes any legal liability or responsibility for the accuracy, completeness, or usefulness of any information, apparatus, product, or process disclosed, or represents that its use would not infringe privately owned rights. Reference herein to any specific commercial product, process, or service by trade name, trademark, manufacturer, or otherwise, does not necessarily constitute or imply its endorsement, recommendation, or favoring by the United States Government or any agency thereof. The views and opinions of authors expressed herein do not necessarily state or reflect those of the United States Government or any agency thereof.

Publishing support services were provided by Argonne's Information and Publishing Division. (For more information, see IPD's home page: http://www.ipd.anl.gov.)

Available electronically at these sites:

•http://www.arm.gov/docs/sites/sgp/internal/ ssmp13.pdf

$\bullet$ http://www.doe.gov/bridge

Paper copies available to DOE and DOE contractors from the Office of Scientific and Technical Information, P.O. Box 62,

Oak Ridge, TN 37831; prices available from (865) 576-8401.

Available to the public from the National Technical Information Service, U.S. Department of Commerce, 5285

Port Royal Road, Springfield, VA 22161. 
ARM-99-002

\section{Site Scientific Mission Plan for the Southern Great Plains CART Site July-December 1999}

July 1999

Randy A. Peppler, ${ }^{1}$ Douglas L. Sisterson, ${ }^{2}$ and Peter Lamb ${ }^{1}$

${ }^{1}$ Cooperative Institute for Mesoscale Meteorological Studies, The University of Oklahoma, Norman, OK 73019

2Environmental Research Division, Argonne National Laboratory, Argonne, IL 60439

Work supported by United States Department of Energy, Office of Science, Office of Biological and Environmental Research, Environmental Sciences Division 


\section{SITE SCIENTIFIC MISSION PLAN FOR THE SOUTHERN GREAT PLAINS CART SITE JULY-DECEMBER 1999}

\section{INTRODUCTION}

The Southern Great Plains (SGP) Cloud and Radiation Testbed (CART) site was designed to help satisfy the data needs of the Atmospheric Radiation Measurement (ARM) Program Science Team. This Site Scientific Mission Plan defines the scientific priorities for site activities during the six months beginning on July 1, 1999, and looks forward in lesser detail to subsequent six-month periods. The primary purpose of this document is to provide scientific guidance for the development of plans for site operations. It also provides information on current plans to the ARM functional teams (Management Team, Data and Science Integration Team [DSIT], Operations Team, and Instrument Team [IT]) and serves to disseminate the plans more generally within the ARM Program and among the members of the Science Team. This document includes a description of the operational status of the site and the primary site activities envisioned, together with information concerning approved and proposed intensive observation periods (IOPs). The primary users of this document are the site operator, the site program manager, the Site Scientist Team (SST), the Science Team through the ARM Program science director, the ARM Program Experiment Center, and the aforementioned ARM Program functional teams. This plan is a living document that is updated and reissued every six months as the observational facilities are developed, tested, and augmented and as priorities are adjusted in response to developments in scientific planning and understanding.

With this issue, many aspects of the Site Scientific Mission Plan have been moved to ARM sites on the World Wide Web. This report and all previous reports are available on the SGP CART site's Web home page at

$$
\text { http://www.arm.gov/docs/sites/sgp/sgp.html , }
$$

at the link "Site Scientific Mission Plan." 


\section{SUMMARY OF SCIENTIFIC GOALS AND SITE PRIORITIES}

\subsection{Programmatic Goals}

The primary goal of SGP CART site activities is to produce data adequate to support significant research addressing the objectives of the ARM Program. These overall objectives, as paraphrased from the ARM Program Plan, 1990 (U.S. Department of Energy 1990), are the following:

- To describe the radiative energy flux profile of the clear and cloudy atmosphere

- To understand the processes determining the flux profile

- To parameterize the processes determining the flux profile for incorporation into general circulation models (GCMs)

The program plan can be found in its entirety at

http://www.arm.gov/docs/documents/project/er_0441/toc.html .

The SGP CART site is the first of three global locations chosen and instrumented for data collection. As summarized in the Science Plan for the ARM Program (U.S. Department of Energy 1996), the scientific issues to be specifically addressed by using data from a midlatitude continental CART observatory include the following:

- Radiative transfer in cloudless, partly cloudy, and overcast conditions

- Cloud formation, maintenance, and dissipation

- Parameterizations of nonradiative flux

- The role of surface physical and vegetative properties in the column energy balance

- Other complications in the radiative balance in the atmosphere, particularly those due to aerosols, cloud condensation nuclei, and cloud-aerosol radiative interactions 
- Feedback processes between different phenomena and different domains

The variety, surface density, and atmospheric volumetric coverage of the SGP instrumentation will be more comprehensive than those at any other ARM site, and the SGP site will experience a wider variety of atmospheric conditions than will the other sites. The resulting data will accordingly support a greater range and depth of scientific investigation, making it imperative for the ARM Program to develop and maintain a high-quality, continuous data stream from the SGP site. The ARM Program Science Plan can be found at

http://www.arm.gov/docs/documents/technical/sciplan/sp_contents.html .

The measurements required by Science Team proposals, the DSIT, and the science director are categorized into areas or "working groups" of scientific applications within ARM. The DSIT and other teams coordinate activities to develop integrated, well-focused data sets for these groups. Focus areas include shortwave radiation, longwave radiation, water vapor, aerosols, clouds, surface fluxes, and the single-column model (SCM). A goal is to facilitate development of algorithms that prescribe geophysical phenomena as products of multiple data streams. More details on the activities of the working groups can be found at

http://www.arm.gov/docs/research.html ,

under "Science Team Activities."

\subsection{Priorities for Site Activities during This Period — Executive Summary}

This section represents a synopsis of activities scheduled for July-December 1999. More detail on most of the activities is contained in later sections of this document.

Intensive Observation Periods. IOPs during this period will continue to focus on providing critical episodic data sets for the Science Team, as well as on field support for instrument development and for testing and collaborative campaigns. The IOPs scheduled for this period include continuation of the JPL (Jet Propulsion Laboratory) GPS (global positioning system) Campaign, the MCS (Mesoscale Convective Systems) Campaign (May-September), and the MWR (microwave radiometer) Campaign (June-September). Other IOPs and campaigns during this period include the SGP99 Campaign (July 7-22), the summer SCM IOP (July 12-22), the Photoacoustic Campaign (November-December), the International Pyrgeometer 
Intercomparison (September 20-October 1), the DIAL (differential-absorption lidar)/Raman Lidar Validation Intercomparison Campaign (September 23-October 22), the 1999 Fall SCM/NBL (nocturnal boundary layer) IOP in Support of CASES-99 (Cooperative AtmosphereSurface Exchange Study; October 1-31), and the CLEX-5 (Cloud Layer Experiment) Campaign (November 1-21). See Section 5.1.2 for more details on IOPs and campaigns during this period.

Instruments. The Colorado State University SSP-3 (a scanning spectral polarimeter) is again scheduled for deployment at the central facility. This is a much-desired spectral radiometer that would add desired redundancy to spectral radiometry at the SGP site. The U.S. Department of Agriculture (USDA; Lee Harrison) ultraviolet (UV) spectral radiometer is expected to be deployed at the central facility during this period. This instrument was developed with funding from the USDA. Chris Rocken of the University Corporation for Atmospheric Research/GPS Science and Technology (UCAR/GST) is installing a 20- to 30-site GPS micronetwork for water vapor tomography studies in the immediate vicinity of the central facility. This network will be in place in time for any special fall 1999 water vapor measurement activity. The water vapor measuring devices will be left in the field for at least three years as an Instrument Development Program (IDP) initiative. If it is successful, the network will formally become part of the SGP CART site domain. An Eppley total UV radiometer to be added to the Baseline Surface Radiation Network (BSRN) at the central facility will measure total UV radiation. This radiometer will be included in the conversion of the BSRN to a broadband radiometer station (BRS) this summer. An upgrade of the balloon-borne sounding system (BBSS) to use RS-90 sondes may take place during the period. The absolute solar transmittance interferometer will continue to operate in IOP mode as requested. See Section 3.3 for more information on instruments during this period.

Facilities. Surface meteorological observation station (SMOS) tower replacements at all extended facilities should be completed during the period. Operation of the radiometer calibration facility (RCF) will continue with Broadband Outdoor Radiometer CALibrations (BORCALs) during this period, as many as sky conditions permit. Site operations personnel trained by the National Renewable Energy Laboratory (NREL) now perform most of this work. Successful BORCALs were carried out in September 1996 and July-September 1997 and 1998. The phased implementation of the Okmulgee extended facility (the wooded site) will include installation of a solar and infrared radiation station (SIRS) and a SMOS during this period. Eddy correlation (ECOR) components have been ordered for later deployment. A commercially available temperature and humidity calibration chamber was installed just before this period began. The chamber was used successfully to calibrate a chilled-mirror hygrometer for the 
Tropical Western Pacific (TWP) CART site. Phased implementation of two trailers at the IDP-4 location will continue during this period. This area will become a general depot for storage, spare parts, and ready-to-deploy spare instruments for all three CART sites. The area is also being developed to accommodate IOP participants when the need arises. The Cordell extended facility will be moved $100 \mathrm{~m}$ west of its present location during the period because of the construction of a new road. However, the soil water and temperature system (SWATS) and the associated rain gauge will remain at their present location. The Oklahoma Department of Transportation will incur the costs of this move. Two new facilities will be added to the central facility this fall. They are the guest instruments facility trailer at the optical cluster and the instrument maintenance facility trailer near the IDP-3 location. These trailers are expected to be fully functional by December. See Sections 3.7, 7.1.1, and 7.1.2 for more information on site development.

Scientific Support for Site Operations. Data quality algorithm development will continue for data from longwave radiometers, shortwave radiometer shading, and the ECOR.

Development of long-term statistics on data quality metrics performance will continue. Results of data quality efforts by the site scientist can be found at

http://www.res.sgp.arm.gov/sst/dq_monitor/DISPLAYS.html .

During the period, work will continue on Build 2 of the Meta Data Navigator (MDN). The MDN is a new graphical user interface for obtaining ARM data along with an indication of their quality. Build 1 was unveiled in March 1999 for beta-testing purposes. Build 2 will have quick-look capability and a mechanism for submitting Data Quality Reports in batch mode. The Continuous Quality Improvement (CQI) Program will continue throughout the period as more data from extended, boundary, and intermediate sites are assessed. The CQI Program focuses on site and instrument maintenance and site safety for the purpose of improving data quality. Educational outreach tours of the central facility and talks to local groups will be provided as requested during summer 1999, and the Oklahoma Climatological Survey (our SGP outreach partner) will conduct an EARTHSTORM/ARM/Oklahoma Mesonet workshop for Oklahoma and Kansas teachers on July 26-27, 1999. See Sections 4 and 5.3, respectively, for more information on data quality and outreach. 


\section{ROUTINE SITE OPERATIONS}

\subsection{Overview}

The overwhelming majority of the measurements with the highest priority, on which the existing experimental designs are based, are regular routine observations, as specified in the ARM Program Plan, 1990 (U.S. Department of Energy 1990). Scientifically and logistically, routine operations also serve as the basis and background for all nonroutine operations, including instrument development activities, IOPs, and collaborative campaigns directed toward obtaining difficult-to-gather or expensive in situ data. Consequently, development and validation of the basic observations remain high priorities. The SGP site is sufficiently mature to support IOPs addressing key scientific areas of study.

Routine operations are the activities related to the operation and maintenance of instruments; the gathering and delivery of the resulting data; and the planning for scientific investigations, including IOPs, campaigns, value-added products (VAPs), and quality measurement experiments (QMEs). Although the site is essentially complete, instrumentation is evaluated continuously to assess its effectiveness in helping to meet the ARM Program's goals for the SGP site.

The design expectation for the routine operation of instruments is that they will continue to require servicing by site operators only once every two weeks. The exception to this is the central facility, which is staffed. If an instrument failed during a two-week period at an extended facility, communication, data streams, or both could be lost, although every effort is made to ensure that data-logging capacity is adequate at each location.

Site operations staff conduct additional instrument "triage" during IOPs and campaigns. The triage plan calls for IOP scientists to identify instruments, individual sensors, and communication links that are critical to the operation and goals of the IOP, so that these instruments can receive more frequent servicing than is prescribed by the routine operational requirements mentioned above. The priority of triage efforts is determined by IOP scientists, the SST, and the site program manager, who take into consideration the scientific importance of a particular data stream and its expense.

Because an electronics facility was implemented at the central facility last year, many repairs and calibrations can now be made on the site. Handling of instruments that must be 
returned to the vendor for calibration and servicing is also part of routine operations. Replacement instruments and sensors are rotated regularly to meet these requirements. Calibration and maintenance information is compiled, both to operate and maintain site instruments properly and to provide pertinent information to data users. Changeouts of all sensors and instrumentation are recorded in the site operations log.

This past spring, a temperature-relative humidity calibration chamber was installed at the central facility. The system has already been used to verify calibrations of the aspirated psychrometers used during preventive maintenance checks for SMOS instruments at each of the extended facilities. In addition, the chamber has been used to intercompare SGP and TWP chilled hydrometers. Steps are being taken to modify the chamber so that SGP technicians can perform and certify calibrations for temperature and humidity sensors for all three CART sites.

Initial checks of data quality after instrument installation are provided by the instrument mentors. After the mentor reviews the data stream to ensure that the acquired instrument is performing properly and that the data are identified accurately by the Experiment Center, the mentor approves a "beta" release of the data. The beta release provides data to selected Science Team members who have requested them and are willing to work with the instrument mentor on data quality issues. Beta releases are established after the instrument mentor and an appropriate member of the DSIT have created a general statement on data quality for the Experiment Center. When the data quality relative to proper instrument functionality is consistently acceptable and well documented, the mentor approves a full release of the data.

For more information about routine observations, instrument and facility logs and maps, operational status data, logistics support, instrument inventory, operations procedures and plans, and site safety, visit the Operations Management Information System (OMIS) at

$$
\text { http://www.ops.sgp.arm.gov/ . }
$$

\subsection{Routine Operations}

\subsubsection{Functional Instruments and Observational Systems}

Figure 1 is a map of the SGP site showing the locations of the developed extended, intermediate, and boundary facilities. The status of the systems and instruments anticipated by December 31, 1999, is summarized in Table 1. 


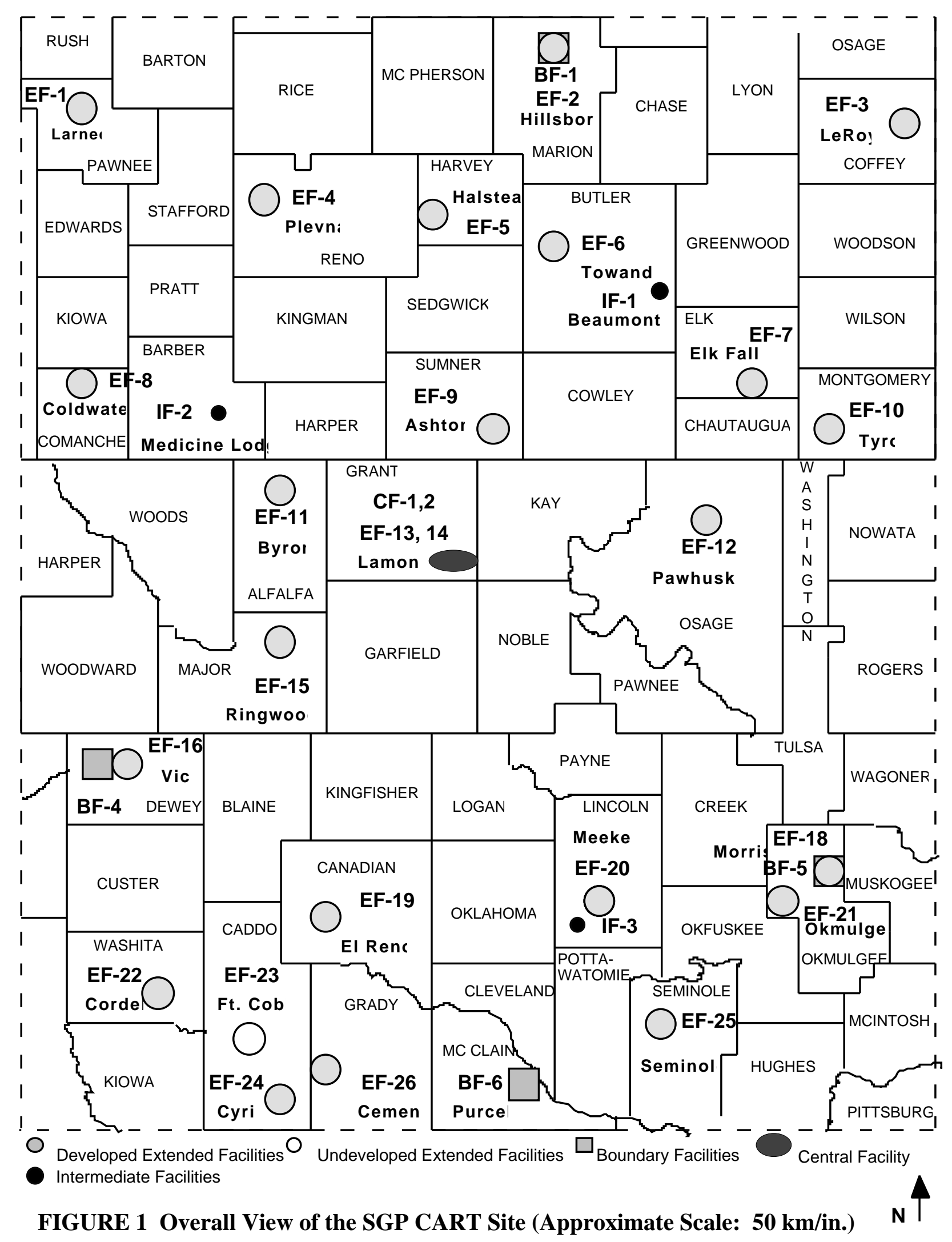


TABLE 1 Instruments and Observational Systems Anticipated at the Central, Boundary, Extended, and Auxiliary Facilities on December 31, 1999a

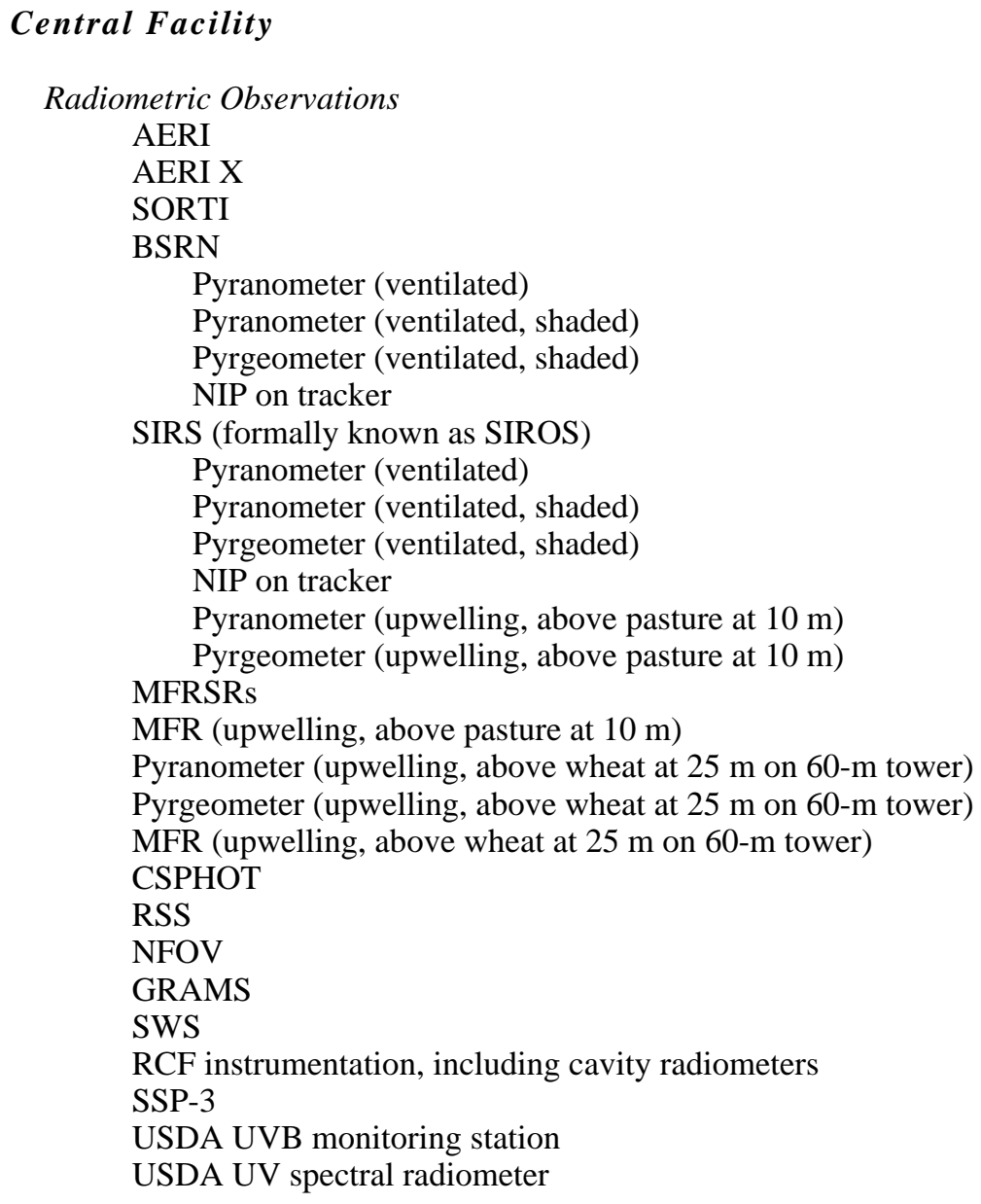

Wind, Temperature, and Humidity Systems

BBSS

915-MHz profiler with RASS

50-MHz profiler with RASS

MWR

Heimann IR thermometer

Raman lidar

THWAPS

Cloud Observations

WSI (daytime/nighttime)

BLC (interim)

MPL-HR

MMCR

TLCV 


\section{TABLE 1 (Cont.)}

Others

Temperature and humidity probes at 25-m and 60-m levels on tower

Heat, moisture, and momentum flux instrumentation at 25-m and 60-m levels on tower

EBBR

ECOR

SMOS

AOS (samples at $10 \mathrm{~m}$ )

SWATS

\section{Extended Facility Components}

SIRS (formally known as SIROS)

Pyranometer (ventilated)

Pyranometer (ventilated, shaded)

Pyrgeometer (ventilated, shaded)

NIP on tracker

Pyranometer (upwelling, at $10 \mathrm{~m}$ )

MFRSR

Pyrgeometer (upwelling, at $10 \mathrm{~m}$ )

EBBR or ECOR

SMOS

SWATS

\section{Auxiliary Facilities}

None in preparation

\section{Boundary Facilities}

BBSS

MWR

THWAPS

VCEIL

AERI

\section{Intermediate Facilities}

915-MHz profiler and RASS

a AERI, atmospherically emitted radiance interferometer; AOS, aerosol observation system; BBSS, balloon-borne sounding system; BLC, Belfort laser ceilometer; BSRN, Baseline Surface Radiation Network; CSPHOT, Cimel sunphotometer; EBBR, energy balance Bowen ratio; ECOR, eddy correlation; GRAMS, ground-based radiometer autonomous measurement system; IR, infrared; MFR, multifilter radiometer; MFRSR, multifilter rotating shadowband radiometer; MMCR, millimeter cloud radar; MPL-HR, micropulse lidar-high resolution; MWR, microwave radiometer; NFOV, narrow-fieldof-view zenith-pointing filtered radiometer; NIP, normal-incidence pyrheliometer; RASS, radio acoustic sounding system; RCF, radiometer calibration facility; RSS, rotating shadowband spectrometer;

SIROS, solar and infrared radiation observing system; SIRS, solar and infrared radiation station; SMOS, surface meteorological observation station; SORTI, solar radiance transmission interferometer; SSP, scanning spectral polarimeter; SWATS, soil water and temperature system; SWS, shortwave spectrometer; THWAPS, temperature, humidity, wind, and pressure sensors; TLCV, time-lapse cloud video; USDA, U.S. Department of Agriculture; UV, ultraviolet; UVB, ultraviolet-B; VCEIL, Vaisala ceilometer; WSI, whole-sky imager. 
ARM has developed an instrument Web site that provides a detailed description of each instrument and sensor used at each of the three CART sites. Information includes status andlocations, theory of operations, calibration history, examples of data, quality assurance, and citable references. This information can be found at

$$
\text { http://www.arm.gov/docs/instruments.html . }
$$

In addition, ARM has developed a mission-critical Meta Data System (MDS) that enables all information to be provided at a common location (supplementing the instrument data streams). The MDS database enhances the scientific utility of the instrument data streams. Such information is available at the ARM MDS Web site at

$$
\text { http://www.db.arm.gov/MDS/ . }
$$

Additional information about instrument preventative and corrective maintenance, serial numbers, calibrations, etc. can be found in OMIS at

$$
\text { http://www.ops.sgp.arm.gov/ . }
$$

\subsubsection{Launch Schedule for Balloon-Borne Sounding Systems}

The schedule for routine launch operations during this period is in Table 2. The routine radiosonde launch times, approved by the Science Team Executive Committee, were chosen to complement the National Weather Service standard launch times of 0000 and 1200 UTC (universal time coordinated) and to support the daytime satellite advanced very-high-resolution radiometer (AVHRR) overpass at approximately 2030 UTC. In addition, the 2030 UTC launch during the maximum daytime boundary layer height supports instantaneous radiative flux (IRF) research. The midnight launch provides the only deep tropospheric nighttime information. Remote sensing of virtual temperature profiles at all boundary facilities is performed by the nearby National Oceanic and Atmospheric Administration (NOAA) profilers, which are being outfitted with ARM-provided radio acoustic sounding system (RASS) units. The RASS units have already been installed at the Purcell, Oklahoma, and Haviland, Kansas, NOAA profilers. The Lamont, Oklahoma, NOAA profiler will not receive a RASS unit because the location is too close to a residence, but the nearby SGP CART site central facility collects a relative abundance of thermodynamic data. In addition, GPS instruments were recently installed at the Purcell, Vici, Haskell, Haviland, Lamont, Neodesha, and Hillsboro NOAA profiler locations to provide 
TABLE 2 Radiosonde Launch Schedule for July 1-December 31, 1999 (Times in UTC)a

Central Facility $\quad$ Boundary Facilities

June 1-July 11, 1999 (Routine Operations, MondayFriday)

0000

0600

1200

2030

July 12-22, 1999 (Intensive Observation Period, MondaySunday)

$\begin{array}{ll}0000 & 0000 \\ 0300 & 0300 \\ 0600 & 0600 \\ 0900 & 0900 \\ 1200 & 1200 \\ 1500 & 1500 \\ 1800 & 1800 \\ 2100 & 2100\end{array}$

July 23-September 24, 1999 (Routine Operations, MondayFriday)

0000

0600

1200

2030

September 24-October 31, 1999 (Intensive Observation

Period, Monday-Sunday) $b$

$\begin{array}{ll}0000 & 0000 \\ 0300 & 0300 \\ 0600 & 0600 \\ 0900 & 0900 \\ 1200 & 1200\end{array}$

November 1-December 31, 1999 (Routine Operations,

Monday-Friday)

0000

0600

1200

2030

a UTC, universal time coordinated. Launch time is 30 min earlier; the stated time represents the approximate midpoint of the flight.

b Only the Hillsboro and Morris boundary facilities are participating for the period October 1-31, 1999. 
estimates of precipitable water. This information, along with the NOAA profiler data, has become available to the ARM Program as external data.

The central facility is staffed from 0530 to 2030 CDT (central daylight time) (0430-1930 CST [central standard time]) and from 2330 to 0330 CDT (2230-0230 CST), Monday through Friday (including holidays, although staffing is limited). During normal SCM IOPs, the central facility and the four boundary facilities will be staffed 24 hours per day, 7 days per week (including holidays) to facilitate round-the-clock radiosonde releases every 3 hours, centered on 0000 UTC.

\subsection{Instruments}

A CART instrument is any instrument that is approved by the ARM Program and for which the site operations management has accepted responsibility for operation and maintenance. The Pre-Readiness Review and Operational Readiness Review forms represent requests for information to facilitate the installation and operation of instruments or facilities at the SGP CART site. The purpose of such reviews is to achieve an efficient handoff of instruments and facilities from instrument mentors to site operators. When all procedures, operation manuals, and training pertaining to an instrument have been completed, the instrument is accepted by site operations management. If sufficient documentation is available to operate an instrument, even though more will ultimately be required for full acceptance, the instrument may be operated in a degraded mode. The SGP CART instrumentation implementation flow chart is provided elsewhere (page 17 in Peppler et al. 1999).

Instruments recently installed or expected to be installed during this period include the following:

- Absolute Solar Transmittance Interferometer (ASTI), Available. Operation of the ASTI will continue in IOP mode as requested. A permanent location just south of the optical trailer at the central facility was completed in January 1999.

- Scanning Spectral Polarimeter (SSP-3) Addition to the Optical Cluster at the Central Facility, in Progress. Graeme Stephens requested and provided this 
prototype instrument in September 1998. The SSP-3 is not a CART instrument, but it does provide an opportunity for comparison with other instruments. The SSP-3 will be treated as an IDP instrument and will be operated for an extended (indefinite) period. Installation of a revised instrument is planned for late October 1999.

- Eppley 8-48 (Black and White Pyranometer) Radiometer to Replace Shaded Precision Spectral Pyranometer (PSP) in the Solar and Infrared Radiation Station Testbed at the Central Facility, Installed. When it is used to measure diffuse radiation, the Eppley 8-48 does not exhibit the apparent daytime offsets observed by the CART PSP instrument in the SIRS. The Eppley 8-48 was installed in the SIRS testbed at the central facility in early 1999.

- USDA UVB Radiation Monitoring Program Site at the Central Facility, Installed. Dave Bigelow (NREL) requested and received approval for the installation of a small array of instruments, including a multifilter rotating shadowband radiometer (MFRSR) identical to those used by ARM, a UVMFRSR (Harrison design), a Yankee ultraviolet-B (UVB) broadband radiometer, various meteorological sensors, and a data logger. Installation was completed at the central cluster in spring 1999.

- Eppley Total Ultraviolet Radiometer (TUVR) to Be Added to Baseline Surface Radiation Network at the Central Cluster at the Central Facility, Installed. The TUVR will measure total UV radiation and will be included in the conversion of the BSRN to a BRS platform.

- Upgrades of the Balloon-Borne Sounding System, in Progress. Steps have been taken to upgrade the CART BBSSs to use GPS-based rather than loranbased tracking for determining position, a necessity during the next few years as loran- $\mathrm{C}$ transmitters are phased out. In addition, a new type of Vaisala radiosonde, in which the RS-90 sonde replaces the RS-80 version presently used, is expected to become available this year. The humidity sensor on the RS-90 sonde is reported to have a faster response and to recover more quickly after it emerges from clouds. The temperature sensor is smaller and thus is probably considerably faster in response and less susceptible to the effects of heating by solar radiation. Reference temperature, humidity, wind, and 
pressure sensors will be operational at each of the four boundary facilities by 2000.

- Ultraviolet Spectral Radiometer(UVSR), in Progress. A UVSR (Lee Harrison, State University of New York-Albany, with funding from the USDA) should be available for installation in the fall of 1999. This instrument will measure total horizontal irradiance at 290-360 $\mathrm{nm}$.

- Global Positioning System, in Progress. Chris Rocken of UCAR/GST is in the process of installing a 20- to 30-site GPS micronetwork in the immediate vicinity of the central facility. The network will be in place by fall 1999. These water vapor measurement devices will be used to test water vapor tomography techniques. This is a Science Team project, and proof of concept is anticipated to take about three years. If it is successful, the network will become part of the formal SGP CART site domain.

- Small Business Innovative Research (SBIR) Program Microwave Radiometer, in Progress. The U.S Department of Energy (DOE) SBIR Program has awarded a Phase II grant to Radiometrics to test a prototype MWR temperature and water vapor profiler system at the SGP CART site. Installation of this system is planned for late 1999 or early 2000. The MWR profiler will provide tropospheric profiles of temperature and water vapor for nonprecipitation conditions.

\subsection{Baseline Change Request}

Once site operations personnel have accepted instruments, their design and configuration are "locked in" by using a configuration management system that is controlled by site operations personnel. Any modifications to instruments or data systems that could affect more than one ARM functional group require a baseline change request (BCR). The BCR process is in a secure Web-based system. A BCR submittal form can be found at

http://www.twppo.lanl.gov/oms.acgi\$bcr.form.sgp .

The BCR requests usually come from instrument mentors. The site program manager, the control point for the BCR process, assigns infrastructure support for review and approval. Individuals participating in the review and approval process are given passwords for access to the BCR database. An emergency BCR requires response within 24 hours, a critical BCR within 
24-48 hours, a very important BCR within 3-5 working days, an important BCR within 5 working days, and a routine BCR within 10 working days.

\subsection{Development of the Site Data System}

Several installed instruments and all new instruments require software to transfer the data from the instrument platforms to the site data system (SDS) via a pathway referred to as the integrated data processing circuit (IDPC). The IDPC handles communications between the instrument and data loggers and the data ingest system, transfers reports on instrument status to site operations staff and others, and transmits data to the Experiment Center and the Data Archive. The IDPC development schedule and the status of instruments can found at

http://www.res.sgp.arm.gov/SDSMgtSite/application/idpc_status.htm .

\subsection{Observations, Measurements, and External Data}

External data being delivered to the ARM Program can be found on the Web at http://www.xdc.arm.gov/ .

The availability of data from a particular platform on any given day is a function of the quality assurance process; some segments are temporarily unavailable during evaluation or correction of problems.

\subsection{Site Development Activities during This Period}

Establishment of Instruments on an Extended Facility at a Forested Site, in Progress. A walk-up scaffolding tower (approximately $18 \mathrm{~m}$ ) was erected in the summer of 1997 at the Okmulgee extended facility. The tower supports an ECOR system, a SMOS, and a SIRS above the forest canopy. All infrastructure support was completed in May 1998. Phased implementation of instrumentation is scheduled for FY 1999, with SMOS and SIRS installation imminent.

In anticipation of the need for additional IDP area facilities, the IDP-4 location is being developed. This $150-\mathrm{ft}$ by $175-\mathrm{ft}$ graveled area is at the site formerly occupied by the farmhouse at the extreme southeast corner of the central facility. This area has a double-wide trailer ( $24 \mathrm{ft}$ 
by $55 \mathrm{ft}$ ) for storage and an office trailer $(12 \mathrm{ft}$ by $50 \mathrm{ft})$. The storage facility will serve all three CART sites for ready-to-deploy spare instruments and instrument spare parts. Phased development, including power distribution centers and communications, will continue during this period.

A major ongoing activity is the replacement of 22 SMOS towers at the extended facilities and the central facility. The new towers are lightweight, single-mast, counter-weighted, tipping structures that require no guy anchors. The replacement activity has been led by Dan Nelson, and Wayne Meadows is the technical safety representative in the field. A subcontractor will install the towers. The activity is expected to be completed by October 1999.

The optical trailer, the RCF trailer, and the Raman lidar and cloud radar shelters are protected by automatic fire suppression systems using carbon dioxide. A thorough review and testing of these systems occurred in August 1998, after an incident resulting in the accidental discharge of a similar system and a fatality at a DOE-managed facility in Idaho Falls. Although the SGP systems were in compliance, additional review led to the removal of the systems in the optical and RCF trailers to reduce the risk to personnel and visitors. The carbon dioxide systems in the Raman lidar and cloud radar shelters remain operational.

The Cordell extended facility will be moved during this period because of new road construction. The new location will be about $100 \mathrm{~m}$ west of the present location. The SWATS and the associated rain gauge will remain at the present location and will be linked to the new site by fiber-optic cabling. The Oklahoma Department of Transportation will subsidize the move. Dan Nelson is in charge of the project.

Two new trailer systems will be added to the central facility: the instrument maintenance facility (IMF) trailer and the guest instrument facility (GIF) trailer. The IMF is a triple-wide Argonne surplus trailer that will provide a 36-ft by 66-ft facility for consolidating instrument parts, repairs, and an electronics laboratory, as well as for additional office space and restrooms. This facility will be located just east the conference trailer and southwest of the IDP-3 location. The GIF is a double-wide Argonne surplus trailer that will provide a $24-\mathrm{ft}$ by $52-\mathrm{ft}$ space for guest instruments, to be located just north of the optical trailer. These trailers have been shipped to the SGP CART site, and the implementation design phase is nearly complete. The trailers will be operationally ready in time for the March 2000 IOP activities. 


\section{DATA QUALITY}

Data quality issues are addressed at several levels within the ARM Program and at the SGP CART site. One of the primary goals of the ARM Program is to provide data streams of known and reasonable quality. Maintaining data quality for a program of this size and complexity is a significant challenge. Data quality assurance within the ARM Program infrastructure has matured over the past few years and will continue to evolve, with the SST continuing to play a significant role. Data flagging issues, development of a mechanism for displaying information on data quality to data users, and addressing data quality for new instruments continue to be the focus for this six-month period.

\subsection{Instrument Mentors}

Instrument mentors are charged with developing the technical specifications for instruments procured for the ARM Program. The instrument mentor then tests and operates the instrument system (either at his or her location or at the SGP CART site). In addition, the mentor works with SDS personnel on data ingest software requirements as part of the IDPC. Data ingest involves the conversion of data streams to the International System of Units (SI), as well as the acquisition of parameters that can be used to monitor instrument performance (e.g., monitoring an instrument's output voltage for a $5-\mathrm{V}$ power supply or the continuity of the wire in a hot-wire anemometer). Data collection and data ingest, then, are the focus of the first level of data quality assurance. Quality at this level is monitored routinely by instrument mentors and site operators.

The next level of data quality assurance involves beta release of data streams from individual instruments. The mentor receives the data from the instrument to determine whether the technical specifications of the instrument are being met. When the mentor is satisfied that the instrument is functioning properly and that the technical specifications have been met, the data are formally released to the Science Team and other data users. After this release, the instrument mentor is charged with reviewing the instrument data streams at least once every two weeks, an action monitored at the Experiment Center. This information is forwarded to the SST.

Instrument mentors provide all calibration, operations, and maintenance documents and lists of spare parts to site operations. Typically, the mentor provides additional detailed documentation and hands-on training so that appropriate support can be offered by site operators. 
This activity is part of the Operational Readiness Review process. More details on instruments or data quality activities can be found at

http://www.arm.gov/docs/sites/sgp/sgp_instruments.html

under the listings for individual instruments.

\subsection{Site Scientist Team}

The SST helps to ensure that the scientific productivity of the SGP CART site is maximized by both the routine and special (IOP) operations at the site.

Data quality assessment efforts of the SST involve evaluation of individual and multiple sets of data streams as needed, on an exploratory or developmental basis (data quality investigations); participation in QMEs; and participation in the development of QMEs and VAPs.

The comprehensive, systematic assessment of SGP data stream quality is manifested in several ways, including the development of automated graphic display techniques for use by the SST in daily monitoring of data quality (initiated in October 1995), the development of performance metrics that systematically determine the percentage of the collected data falling within given quality tolerances (initiated in February 1996), and evaluation of the calibration and maintenance information.

The development of performance metrics is aimed at determining the quality of the site data via time series (numerical and graphic) of the metrics. In late 1996, the SST began issuing assessments of the data from several instruments, with the goal of quicker resolution of instrument and data quality problems. In 1998, a Web site containing automatically generated graphic displays of performance metrics and other quality assessment techniques was established at

http://www.res.sgp.arm.gov/sst/dq_monitor/DISPLAYS.html .

This site contains up-to-date information on the quality of SGP data streams. 
Plans for this six-month period include continued development of graphic display techniques for more data streams, continued development and display of performance metrics, continued evaluation of the calibration and maintenance information, and continued participation in an ARM-wide data user interface initiative (the MDN) that will make information on data quality more readily available to data users. The SST is also constructing summary statistics describing long-term metrics performance. See Peppler and Splitt (1998) for more information about ARM SGP data quality techniques.

\subsection{Value-Added Products and Quality Measurement Experiments}

Unlike many other scientific projects, ARM collects data in an ongoing, continuous manner. Because of the volume of the perpetual data streams, traditional case study methods for analyzing the data are not very effective. To meet the need for an automated analytical approach, the concept of a VAP was defined. A VAP creates a "second-generation" data stream by using existing ARM data streams as input and applying algorithms or models to them. A VAP is run continuously in the ARM Experiment Center, and the output generated is treated as a new ARM data stream. The VAPs in the special class called QMEs compare different data streams for consistency and allow for continuous assessment of the quality of the data streams. These data streams may come from direct measurements, measurements derived from instrument observations via other VAPs, or model output that is currently created by other VAPs.

More information on development and on specific VAPs and QMEs is available on the Web at

http://www.arm.gov/docs/research/vap_homepage/vap.html .

\subsection{Meta Data Navigator}

The tasks of (1) incorporating what is known about data availability and data quality and (2) linking this knowledge directly to individual measurements in a way that is easily identifiable by data users, such as by data flagging, continue to be accomplished through development of the MDN, part of the ARM information architecture.

Within the MDN, a communication interface about data availability is being established by color-coding measurements obtained from a particular instrument, with different colors to indicate the availability of data and the quality of the data for a daily aggregate. Pointers direct 
the data user to details of the particular data quality inspection methodology for each measurement. For example, all existing data are color-coded white. Missing data are colorcoded black. Data reviewed by an instrument mentor and judged to be of acceptable quality are color-coded green. Suspect data values are color-coded yellow. Data identified as not usable are color-coded red. The color of the data changes to reflect the most current view of the quality of the measurement. The entire process is automated with a manual override capability. The first version of the MDN, delivered in March 1999, contained all of these features. In addition, a plan is being defined to assign a data quality flag to each existing data value. The flagging system will determine the color of the data and will be part of the MDN's second version, scheduled for completion in FY 2000. Quick-look plots are currently being considered for inclusion in the MDN. These plots are intended to provide the data user with a visual data inspection capability, especially if data are color-coded yellow and require further inspection and interpretation. A Web site for the second version of the MDN will be developed during this period.

\subsection{Problem Review Board}

The problem-reporting system has several components. The process begins with the completion and submission of a Problem Identification Form (PIF). The PIFs are received by the Problem Review Board (PRB), which is composed of representatives from the DSIT and the IT, along with the site program managers. The PRB meets weekly via teleconference and assigns responsibility for analysis and resolution. Resolution is documented in a Corrective Action Report (CAR). A copy of the CAR is sent to the originator of the PIF to ensure that resolution of the problem is communicated.

In addition, a Data Quality Report (DQR) may be required. A DQR is a statement about the quality of data from a particular instrument. The information could be quite simple (e.g., stating that an instrument system was turned off and the data do not exist) or quite complex, giving detailed analyses and equations that should be used to adjust the instrument's data. Hence, the description of the problem and the solution must be complete, so that someone can accurately correct the data.

The PIF, CAR, and DQR forms are accessible from multiple points on the ARM Web site. The PIF/CAR/DQR database can be found on the Web at

http://www.db.arm.gov/PIFCARDQR/ . 


\section{SCIENTIFIC INVESTIGATIONS AND OPPORTUNITIES}

\subsection{Intensive Observation Periods}

The SGP CART site operates a vast suite of instrumentation that routinely provides continuous data streams at a prescribed rate. These rates, however, can be changed upon request. Requests from inside and outside the ARM Program can be made either (1) to operate an ARM instrument or instruments at a different data collection rate or in a different mode of operation or (2) to support and compare non-ARM instruments with ARM instruments. Such periods of special operation are referred to as IOPs.

\subsubsection{Scheduling IOPs}

Requests for IOPs may come through the ARM Program management office (technical director), the SGP CART site program manager's office, or both. The initial requests may be made informally, but an abstract of the goal(s) of the experiment(s) being requested, a list of the potential instruments and platforms involved, and the time period of the experiment(s) must be provided for approval. The requester must identify points of contact for coordination.

Approval of an IOP is an external process that requires (1) review for resources and relevancy and (2) approval by the ARM Program technical director, the SGP CART site program manager, the SST, and site operations staff. After approval, the management of the detailed operational planning, setup, conduct, and shutdown of the IOP is the responsibility of the site program manager. An IOP is given a title and assigned a DSIT representative, who has the responsibility to obtain the relevant scientific information about the proposed activity, typically in a science plan. The DSIT representative informs the appropriate ARM Science Team members of the proposed activity for the purpose of potential collaboration. The site program manager obtains from the DSIT representative a list of potential principal investigators (PIs) and the instruments or systems that are intended to be located at the SGP CART site. The site program manager has PIs fill out IOP questionnaires to collect information about the operational, safety, and data requirements of the IOP. The IOP questionnaires are posted on the IOP Web site, and appropriate ARM infrastructure personnel are notified for review. The IOP questionnaire can be completed electronically by a PI on a Web site at

http://www.arm.gov/stdocs/internal/iop_form.html . 
A complete description of past IOPs can be found at

http://www.arm.gov/docs/iops.html .

\subsubsection{IOPs and Campaigns Scheduled for This Period}

Details on IOPs and campaigns planned or proposed for this period can be found on the Web at

http://www.arm.gov/docs/iops.html .

Synopses of these events are given below.

MCS Campaign (May-September 1999). The MCS Campaign is investigating the precipitation microphysics and convective dynamics of MCS in midlatitudes by using a combination of RASS wind profiler and dual polarimetric scanning radar. Specific goals include (1) development of a profiler retrieval technique for hydrometeor distribution in the ice and mixed-phase regions of MCS and (2) investigation of the precipitation, kinematic, and dynamic characteristics of deep convection. The latter objective includes comparison of the vertical structure of the hydrometeor size distribution, latent heat effects, and potential vorticity production from MCS in both the midlatitude and tropical environments. The 1999 activity is focused on the 50-MHz radar wind profiler (RWP) at the central facility, which is to run in continuous RASS mode for periods of about an hour and collect vertical flux data during convective precipitation events in order to determine the drop size distribution of the precipitation.

Two beneficial by-products of this campaign were achieved through testing of the 915and 50-MHz RWPs and the millimeter cloud radar (MMCR) in April 1999. Ken Moran of the NOAA Environmental Technology Laboratory (ETL) and Peter May of the Australian Bureau of Meteorology (the chief scientist for the MCS Campaign) conducted this work. For the 50-MHz RWP, special test equipment determined that the computer-generated audio signal had proper width and amplitude characteristics and produced a good acoustic signal for the RASS. However, wind and RASS sensitivities were limited by a receiver noise problem. A further analysis of the network noise is necessary to determine a method for reducing the noise level and improving the performance of the 50-MHz system. Testing of the MMCR revealed that the power output of the instrument could be increased 1-2 $\mathrm{dB}$ by changing the setting of the attenuator on the up-down converter, although doing so might shorten the life of the traveling- 
wave tube amplifier. Moran and May also found, for both RWPs, that using algorithms that lessen the effects of backscattered signal from birds seems to reduce the interfering effects on MMCR data of echoes from insects. Further analyses will be carried out to evaluate the beneficial effects of the algorithms.

SGP99 Campaign (July 7-22, 1999). The USDA will conduct a campaign this summer as part of its ongoing Hydrology Experiment. The SGP99 Campaign, to consist of a reduced version of SGP97, has three primary objectives. These are (1) development of soil moisture retrieval algorithms for the Earth Observing Systems-Afternoon Crossing (Descending) Mission (EOS-PM) advanced microwave scanning radiometer (AMSR) by using an aircraft prototype; (2) testing of the feasibility of soil moisture retrieval from the Tropical Rainfall Measuring Mission microwave imager; and (3) evaluation of multifrequency, multipolarization active/passive information by using a new JPL aircraft instrument. To accomplish these goals, USDA has requested cooperation and assistance in a number of areas. These include (1) nearreal-time and archive access to ARM SGP data, (2) access to central facility grounds for soil moisture sampling, (3) access to the lands of adjacent landowners for soil moisture sampling (4-10 fields), and (4) additional sonde launches at the central facility to support correlation of satellite radiometer data with regional water and energy balance modeling. The dates for this campaign are firm.

SCM IOP (July 12-22, 1999). The SCM IOP is being conducted in support of SGP99 activities. The SCM working group has determined from past IOPs that five consecutive days are sufficient for model validation. This means that the original concept of a 21-day SCM IOP can become more flexible. This 10-day SCM IOP not only supports the SGP99 effort but will also allow the SCM working group to evaluate the use of remote sensing information to drive SCMs for convective cases, reducing the dependence on rawinsonde.

ETL GPS Campaign (summer or fall 1999). NOAA/ETL, along with Russian colleagues, is interested in acquiring GPS and water vapor data near the central facility. This activity remains in the planning stages, but the time frame is uncertain.

International Pyrgeometer Intercomparison (September 20-October 1, 1999). The Longwave Working Group is hosting an International Pyrgeometer Intercomparison among BSRN members. The activity is being co-hosted at the central facility's RCF by Joe Michalsky and Tom Stoffel. The intercomparison is limited to working standards and standards rather than encompassing field instruments to keep the number of participants to a practical size. The Sci- 
Tek trackers on the RCF will hold the pyrgeometers. Data streams will be collected by the RCF/NREL data system.

DIAL/Raman Lidar Validation Intercomparison Campaign (September 23-October 22, 1999). The Jens Boesenberg DIAL system (from Germany) will be brought to the central facility for intercomparison and validation with the CART Raman lidar. This activity is being coordinated with the Water Vapor Working Group. Increased sonde launch activity requested for the central facility during this exercise is shown in Table 2. The German DIAL will return to the central facility in September 2000 for the next formal Water Vapor IOP. (See AFWEX in Section 7.2.)

JPL GPS Campaign (June 1998-October 1999). A precision differential GPS, one radiometric MWR (identical to the ARM MWR at the central facility), one JPL-designed MWR, a temperature-profiling radiometer, and a surface meteorological station (similar to the SMOS at the central facility) were installed in June of 1998. The purpose is to calibrate GPS water vapor retrieval algorithms in a moist climate. In December 1998, the radiometric MWR and the all three radiometers were removed.

MWR Campaign (June-September 1999). Jim Liljegren is funded by the National Aeronautics and Space Administration (NASA) to use the ARM CART spare MWR at the central facility to measure water vapor along the line-of-sight path from the surface to the JPL satellite as part of the JPL GPS Campaign. The MWR data will be used for comparison with the JPL GPS receiver data. The ARM Program has received a request to make these GPS-tracking measurements routinely in support of Chris Rocken's ARM project.

Fall SCM/NBL IOP in Support of CASES-99 (October 1-31, 1999). CASES is conducting an intensive NBL experiment near the Atmospheric Boundary Layer Experiments (ABLE) central facility near Witchita, Kansas. The CASES-99 effort focuses on the NBL conditions that drive the low-level wind maxima and other features of the nighttime lower troposphere. Additional soundings by the ARM Program at the SGP central facility and at the Hillsboro and Morris boundary facilities will be deployed as shown in Table 2. These additional soundings will broaden the scales from those of the finer CASES-99 NBL results to the larger scales of interest to ARM.

CLEX-5 (November 1-21, 1999). The University of North Dakota Citation aircraft will be used to obtain in situ measurements of the microphysical properties of midlevel 
nonprecipitating clouds, while satellite and CART instruments are being used to gain a better understanding of the bulk radiative properties of these clouds.

Photoacoustic Campaign (November-December 1999). John Ogren will conduct a NOAA-funded proof-of-concept study to see how the use of complementary methods can improve confidence in measurements of aerosol light absorption. Specifically, a 3- to 4-week intercomparison of instrumentation, to include photoacoustic instruments, aethaleometers, nephelometers, and particle soot absorption photometers, is proposed for installation in the SGP CART aerosol observation system at the central facility.

\subsection{Scientific Working Groups}

The ARM Program has formed groups concentrating on the study of geophysically significant phenomena such as water vapor (atmospheric state), aerosols, clouds, and radiation. Development of algorithms to describe these phenomena is currently a primary focus.

One goal of these groups is to produce algorithm products that represent a merging of appropriate instrument measurements into a cohesive product defining a particular geophysical state, for use by the Science Team. These products specifically address problems posed in the Science Plan (U.S. Department of Energy 1996) and by the various science applications working groups. More information on the activities of the working groups can be found under "Science Team Activities" at

http://www.arm.gov/docs/research.html .

\subsection{Educational Outreach}

The educational outreach program for the SGP CART site, coordinated by Ken Crawford, Director of the Oklahoma Climatological Survey, combines a range of resources available at the University of Oklahoma. Outreach is focused at the precollege, undergraduate, and graduate levels. Efforts in this six-month period will concentrate on professional development activities, staff support for teacher participants, scientific mentorship of students, development of data analysis tools for students and teachers, and application of data in the classroom (McPherson and Crawford 1996; Melvin and McPherson 1998). A two-week workshop involving five Kansas and two Oklahoma teachers was held at the university in July 1997. Instruction on how to use ARM data and related software was given, along with lessons on atmospheric radiation, energy 
transfer, meteorological data, telecommunications, data visualization, the Web, and the ARM Program. Six EARTHSTORM teachers attended the workshop as the "Storm Team," helping instruct participants and offering insight on ways to modify existing lessons and materials to incorporate ARM data. The five Kansas teachers were given Power Macintosh 5400 computers for their classrooms. The Storm Team and other ARM teachers made presentations at the 8th Symposium on Education, held at the 79th Annual Meeting of the American Meteorological Society in Dallas, Texas, in January 1999.

An EARTHSTORM/ARM/Oklahoma Mesonet teacher workshop will be held at the University of Oklahoma July 26-27, 1999. Schools can access ARM data on the Web at

http://www.arm.gov/docs/education.html .

An SGP-only outreach site can be reached from this location through the link "Outreach Sites," by selecting "Southern Great Plains," or by going directly to

http://outreach.ocs.ou.edu/arm/ . 


\section{DISTRIBUTION OF DATA}

Most of the data being requested are received from the SGP CART site or external data sources and are then repackaged for daily and weekly distribution to individual users. In some

special cases, users can log into the Experiment Center or the R1 computer at the central facility and extract data by anonymous file transfer protocol (FTP). All data are sent to the Data Archive, where they are accessible to the public on the Web at

$$
\text { http://www.archive.arm.gov . }
$$

The status of data streams from CART instruments and external sources has been classified as follows:

- Releasable - released upon request for the data stream.

- Developmental - released only to SDS personnel for development of ingestion programs.

- Under evaluation - released to an investigator for an initial data quality check.

- Beta release - for releasable data of known and reasonable quality.

- Collecting — when raw data are being collected for future processing and distribution.

- Mentor only - provided only to the instrument mentor at the request of the mentor.

- Analysis - released for further processing or analysis, such as for graphic display.

- Defunct - due to replacement of a prototype instrument data stream with the CART instrument data stream. 


\section{LOOKING AHEAD}

The SGP CART site now provides a full range of data streams needed to support the broad spectrum of Science Team research. Research activities increasingly draw on multiple SGP data streams to focus on geophysically significant phenomena (water vapor profiles, clouds, aerosols, temperature profiles, radiation, surface fluxes). The most important operational challenges beyond 1999 will therefore include maintaining the performance of the basic instrumentation suite at the highest possible level and improving that performance where possible, enhancing the original CART design through the permanent addition of new instruments, evaluating the effectiveness of current instrumentation, and mounting focused IOPs and campaigns involving temporary additional instrumentation. These activities can meet the evolving scientific requirements, challenges, and opportunities for the SGP CART site. Here we outline the path ahead and issues for 2000 and beyond, to the extent possible in mid 1999.

\subsection{Routine Operations}

\subsubsection{Instruments and Measurements}

Much of the information on instruments in this section is courtesy of Marv Wesely, head of the ARM Instrument Team.

AOS. Scientists at the NOAA Pacific Marine Environmental Laboratory (PMEL) have suggested use of the central facility aerosol observation system (AOS) trailer to measure selected chemical properties of the aerosols sampled through the AOS aerosol inlet. Filters will be used to collect daily samples of submicron particles for analysis of total aerosol mass and of major anions and cations by ion chromatography. In addition, filters will be collected weekly for similar analyses on particles with diameters of about 1-10 $\mu \mathrm{m}$. PMEL will conduct the analyses and post the results on a Web site and preferably will provide the data to the ARM External Data Center. ARM personnel have assessed the costs of assistance with installation and operation of the aerosol collection equipment. Although the aerosol chemistry systems required for filter sampling are in place and site operations personnel have been trained in the procedures, PMEL has not implemented the activity.

Aerosol Observation System by Aircraft (AOSAIR). Discussions are under way, per suggestion of the Aerosol Working Group, to make routine in situ measurements of boundary 
layer aerosols over the central facility by using a light aircraft. The aircraft would be based in the local area.

AERI-X. Continued operation of the high-resolution atmospherically emitted radiance interferometer (AERI) in cooperation with the University of Denver is under discussion. Additional resources would be needed. A significant question is whether the AERI-X data would be used effectively by the ARM Science Team for important ARM research.

Cavity Radiometer. Continuous direct-beam solar irradiance measurements with a cavity radiometer remain under discussion. Documentation for the BSRN specifies that an all-weather windowless cavity radiometer is to be operated at a BSRN site. Because of dusty conditions at the central facility, this is not immediately feasible. Operation of a windowed cavity radiometer might be possible at the RCF, but considerable effort would be needed for continuous operation. Some compromise for part-time or discontinuous operation might be required. Cavity radiometers were operated at the RCF during the Fall 1997 Integrated IOP and during past BORCAL operations.

Chilled-Mirror Hygrometers/Temperature and Humidity Calibration Chamber. Two chilled-mirror hygrometers have been modified by Scott Richardson and are ready for deployment when needed, such as during IOPs. Each hygrometer has a calibration traceable to National Institute of Standards and Technology and is accompanied by a temperature sensor and a supplementary relative humidity sensor. The chilled-mirror devices now have an air filter mounted outside the enclosure to facilitate filter changes. A chilled-mirror hygrometer that operates routinely near the BBSS launch point at the central facility will be upgraded to a configuration similar to that of these two special-use hygrometers. The hygrometers will be returned to the manufacturer every year or two for recalibration, and they will be checked periodically with the SGP site's new temperature-humidity calibration chamber. A manifold assembly has been added to this chamber to decrease calibration time and to enable simultaneous calibration of as many as five temperature and humidity sensors. Temperature and relative humidity profiles have been developed to test sensors from 0 to $+25^{\circ} \mathrm{C}$. The chamber's performance at -20 and $+40^{\circ} \mathrm{C}$ will also be tested. Sensors from all three ARM CART sites will be calibrated in this chamber.

Cloud and Aerosol Optical Depths. The Cloud Working Group would like to see routine computation of cloud optical depth across the CART site. This quantity, which links cloud properties to radiation, could be retrieved from the MFRSR. At the central facility, this quantity 
could be retrieved from a number of instruments, including the Cimel sunphotometer (CSPHOT). Likewise, aerosol optical depth could be computed.

CSPHOT. More angular information could be recorded from the CSPHOT. At present, the instrument scans up to 40 degrees on each side of the sun. The additional angular information would be helpful to the Shortwave Working Group.

Electronics Laboratory. A new electronics laboratory, for use by all three CART sites, is now operational at the SGP. This laboratory allows technicians to service and repair instrument electronics in-house rather than sending them to vendors (with increased repair turnaround time). This new capability is estimated to save ARM \$50,000 per year.

GRAMS. Calibrations for the total broadband solar radiometers were completed in early 1999, and plans were made to implement the calibrations to begin producing appropriate data streams. The ground-based radiometer autonomous measurement system (GRAMS) has been fielded for nearly two years without production of calibrated values. Work continues on arranging for calibrations and acquisition of new filters for the fractional solar broadband radiometers. Operation of one GRAMS instead of two has been suggested.

MFRSR. Discussions continue on how to upgrade the MFRSRs. The SGP units need to be made as reliable as possible. The level of effort needed to upgrade the MFRSRs at all SGP extended facilities appears to be excessive, however, especially in view of the various problems involving filter drift, characterization of the cosine response of the heads, initial calibrations, temperature sensitivity, and alignment. One of the scientific needs for the extended facility MFRSRs might be generation of data on cloud optical depths, but the benefits must be considered versus the costs of producing the desired data streams. It is generally agreed that these improvements will be made to the central facility MFRSRs.

MMCR. Experiments involving improvement of the MMCR were conducted in April 1999 and are described in Section 5.1.2 for the MCS Campaign. In addition, Mark Miller of Brookhaven National Laboratory reports that each step in the calibration adjustment process is being reviewed to ensure that the data reprocessing strategy being conducted is sound. Work continues on mitigating the effects of insects on radar returns.

Optical Transmissometer. A commercially available transmissometer might be acquired to detect fog, dust, and drizzle too light to be recorded by rain gauges. Such phenomena are best 
detected by open-path devices rather than through a large sampling stack like that used by the AOS. The data generated by such an instrument would be useful for evaluating signals from radars, lidars, and the MWR.

Ozonometer. The use of a hand-held ozonometer is under consideration. Such a device, used during the Fall 1997 Integrated IOP, can make relatively easy observations of ozone.

Passive Microwave Systems. A passive MWR for obtaining profiles of temperature through clouds could augment profile measurements made with the AERIs at the boundary facilities. The primary advantage of microwave profiling is that it penetrates clouds, unlike any of the other remote sensing systems for water vapor currently in use at the SGP. The DOE SBIR Program has awarded a Phase II grant to Radiometrics to field-test an MWR, a temperature and water vapor profiler that is expected to be deployed at the SGP CART site in early 2000 for testing.

Eppley 8-48 Pyranometers. As described in Section 3.3, an Eppley 8-48 pyranometer was installed at the central facility's SIRS testbed in early 1999. This radiometer replaced the testbed's shaded PSP for a field evaluation of effectiveness. Work at NREL and elsewhere has confirmed that shaded PSPs are subject to offsets in the measurement of diffuse radiation. The 8-48 is engineered to minimize this offset. In addition to use of this device in place of the shaded PSPs, other options for improved diffuse measurements include use of a correction technique recommended by the BSRN organization and the more elaborate procedures of Bruce Forgan.

50- $\mathrm{MHz}$ RWP. Experiments involving the improvement of 50-MHz RWP data were conducted in April 1999 and are described in Section 5.1.2 for the MCS Campaign. The usefulness of these data in particular continues to be discussed. Because this RWP system has had some problems during the past two or three years, care in evaluation of data quality is required to avoid using data collected during problem periods. Rich Coulter, Dave Turner, and Ed Westwater have agreed to evaluate the performance of the 50-MHz system during a selected time period, either the fall of 1999 or 2000 , to generate a recommendation on the future of the system at the SGP.

SORTI. Long-term operation of the solar radiance transmission interferometer (SORTI) at the central facility is under discussion. Additional resources would be needed for routine operations. A significant question is whether SORTI data will be used effectively by ARM Science Team members. 
Spectral Radiometry. The shortwave spectrometer (SWS) and the rotating shadowband spectrometer (RSS) still run too infrequently for the purposes of the Shortwave Working Group. The SWS has experienced frequent measurement difficulties, while the RSS is often off-line for several months at a time for calibration. Installation of the Colorado State University SSP-3, which has been scheduled for months, is necessary for required redundancy at the central facility.

Surface Bidirectional Reflectance. Measurements of surface bidirectional reflectance have been suggested at times for the SGP site. A commercial portable apparatus for rapid acquisition of bidirectional observations of land and the atmosphere (PARABOLA) is available, but the system is not suitable for routine observations. Nevertheless, such observations would be quite useful in interpreting solar reflectances from satellites. A Science Team project is now assessing this observational need.

SWATS. Long-term maintenance plans are being developed for the SWATS, and a full release of the three remaining sites is anticipated within the next year. Degradation issues are starting to surface now that the instruments have been fielded for three years.

UVB and Photosynthetically Active Radiation Sensors. The central facility became an official member of the USDA UVB Radiation Monitoring Program in February 1999. Sensors installed include an MFRSR, a UV MFRSR (with 2-nm pass bands at nominal wavelengths of 300, 305, 311, 317, 325, 332, and $368 \mathrm{~nm}$ ), a Yankee Environmental Systems UVB-1 radiometer (broadband), a downward looking LI-COR radiometer to detect snow cover, a temperaturehumidity probe, and a barometer. More information on this USDA network and its instrumentation, as well as access to the data, is on the Web at

http://uvb.nrel.colostate.edu/UVB/ .

This collaboration should reap rewards in the future.

Whole-Sky Imager. A draft data release statement has been issued for the whole-sky imager (WSI) at the central facility. Much of the statement is applicable to all ARM WSIs. Data being released include calibration files, calibrated radiances with 35- $\mu$ sr resolution for selected sky patches, calibrated-radiance sky images for daytime and nighttime conditions, calibrated-radiance sky movies for daytime and nighttime, summary statistics of patch radiances, calibrated radiances with 35- $\mu$ sr resolution for the full suite of spectral channels, classifications

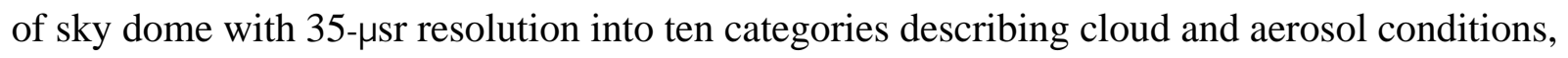


images using false colors to represent the ten categories for daytime or nighttime, and a summary compilation of classification by category and viewed area. Some problems remain with the classification during periods when the solar zenith angle is between 80 and 100 degrees. In addition, SGP WSI calibration for zenith angles greater than 80 degrees is suspect, a problem that affects both the radiance products from this site for these angles and also the classification products.

\subsubsection{Facilities}

Additional Extended Facilities at the SGP CART Site. Some concern has been expressed that the spatial coverage of the extended facilities seems incomplete for measuring air-surface exchange rates of heat and moisture, particularly to the south and southeast of the central facility. The final disposition of the planned Ft. Cobb extended facility has not been determined.

Local Observations of Surface Vegetative Conditions at Extended Facilities. The interpretation of data on, and the modeling of, surface latent and sensible heat fluxes at extended facilities would be assisted by routine observation of leaf area index and surface optical reflectance properties, represented by the non-dimensional vegetative index (NDVI). Relatively simple devices that measure NDVI can be obtained at modest cost. Local measurements of NDVI are believed to be particularly important for interpreting NDVI values derived from remote sensing data obtained by satellites. With local NDVI data, the satellite data could be used to help infer the values and variability of surface heat fluxes over the CART site. This issue remains under discussion.

\subsubsection{Operations}

The following open questions are on the table concerning the operation of the SGP site and its cost effectiveness:

- $\quad$ SCM IOPs. Are three SCM IOPs still required each year at the SGP site? When will remote sensing be sufficient to replace sondes? Do SCM IOPs need to be 21 days long?

- Extended Facilities. Are all 24 extended facilities necessary for adequate surface characterization for GCMs? Do we still need to visit extended facilities every two weeks? 
- AOS. Does the AOS provide sufficient information to study the role of aerosols in radiative transfer in GCMs?

- ECOR. Should ECOR instrumentation be decreased at or eliminated from extended facilities?

- Routine Sonde Launching at the Central Facility. Are four launches per day enough? Should we launch seven days per week instead of the current five?

\subsection{IOPs and Campaigns}

Planning, discussion, or both are under way for a number of proposed IOPs and campaigns for the 2000-2001 time frame. The proposed activities are discussed below.

UAV ARESE Follow-on IOP (February or March 2000). This activity would involve the Twin Otter unmanned aerospace vehicle (UAV) only for an ARM Enhanced Shortwave Experiment (ARESE) follow-on investigation. The IOP would last approximately 4-6 weeks during cloudy conditions, especially during low-level-stratus conditions. The purpose is to address unresolved issues from the original ARESE study by (1) significantly increasing the number of thick-cloud cases studied; (2) providing more spectrally resolved measurements; and (3) where possible, including two independent (different) instruments to measure key properties such as broadband fluxes and spectral radiance. The IOP would coincide with a Cloud IOP during the same period.

Cloud IOP (March 2000). An IOP involving both the University of Wyoming King Air (lower altitudes) and the University of North Dakota Citation (higher altitudes) is being planned. The IOP will examine multilayer and deep cloud systems. Ice crystals within a wide size range from $10 \mu \mathrm{m}$ to several thousand microns will also be imaged. Exactly how this IOP will be conducted is now the subject of discussion within the Cloud Working Group. Because the spring 2000 period includes the Earth Observing System era, some coordination with NASA is being sought to achieve a more thorough experiment that could include participation by the NASA ER-2 and DC-8 aircraft.

SCM IOP (March 2000). This SCM IOP would be coordinated with other March 2000 activities described here to learn more about early spring stratus clouds. 
Shortwave IOP (March 2000). Plans are sketchy as of this writing, but the Shortwave Working Group would like to coordinate activities to support the UAV ARESE Follow-on IOP.

Aerosol IOP (March 2000). The Aerosol Working Group has proposed an IOP to study late winter-early spring conditions. Late winter-early spring clouds on the SGP tend to be stratus-like and therefore represent clouds and aerosol properties that are easier to characterize than those sampled during previous Aerosol IOPs (which sampled fall and later springtime convection). The Pacific Northwest National Laboratory Gulfstream-1 would provide aircraft support.

SCM IOP (Summer 2000). This SCM IOP would concentrate on the more diffuse summertime convection that occurs over the SGP.

Soil Sampling Campaign (Summer 2000). A soil sampling campaign is now proposed for summer 2000 by the University of Miami. This yet unfunded study would investigate the possibility that soils are significant global sinks for atmospheric carbon tetrachloride and chloroform. The campaign would involve soil gas sampling in the top $50 \mathrm{~cm}$ of soil with a small probe and on-site analysis at the central facility by gas chromatography. This campaign would last approximately two weeks.

AFWEX (September 2000). For fall 2000, the Water Vapor Working Group has proposed its third Water Vapor IOP, to be known as the ARM-FIRE Water Vapor Experiment (AFWEX). The IOP will focus on (1) upper tropospheric water vapor measurements, (2) absolute instrument calibration, and (3) an international radiosonde intercomparison. For the upper troposphere, the working group is seeking the participation of the NASA DC-8 to carry DIAL, high-resolution interferometer spectrometer, and Lidar Atmospheric Sounder Experiment water vapor systems and also to make radiance and sunphotometer observations for up to 40 hours of missions. ARM remains in negotiation with NASA over use of its platforms, particularly the DC-8. Desired ground-based measurement platforms include the Jens Boesenberg DIAL, the NASA Goddard Space Flight Center scanning Raman lidar, Ed Westwater and JPL MWRs, and dual sondes. A number of NASA chilled-mirror sondes might be launched during this IOP.

UAV IOP (September 2000). The UAV IOP would be a top-of-the-troposphere mission involving the Altus UAV, perhaps flying above 50,000 feet. This mission would seek to close the "top-of-the-box" problem. Improved operational robustness of both the Altus and ground operations would be the key to this mission. The mission will consist of a simplified flight 
pattern and much less grandiose ground support (as compared to previous UAV missions at the SGP). The aircraft operation will include a more sophisticated sparing strategy to minimize downtime, as the Altus payload will include a complete set of spares for critical measurements. The payload will be preassembled and flight-tested before the mission, minimizing ground fixes. The Twin Otter would be used only as a chase plane.

SCM IOP (September 2000). This SCM IOP would occur in conjunction with the AFWEX experiment to improve characterization of upper tropospheric water vapor conditions.

IHOP/TIMEx Campaign (Spring 2001). The National Severe Storms Laboratory's Thunderstorm Initiation Mobile Experiment (TIMEx) has been restructured into two parts: (1) investigation of upper tropospheric processes and (2) investigation of lower tropospheric/surface processes. The latter component has identified the need for mobile scanning devices to map the low-level moisture field. A pre-TIMEx initiative under a U.S. Weather Research Program grant, known as the International $\mathrm{H}_{2} \mathrm{O}$ Project (IHOP), would occur in spring 2001 and would attempt to involve all available water vapor measurement devices at the SGP CART site to investigate water vapor measurements for (1) thunderstorm initiation, (2) improvement of numerical weather prediction models, (3) improvement of data assimilation models, and (4) study of the relationship between water vapor and quantitative precipitation forecasting. Other goals would include instrument intercomparison and support of design studies for new DIAL systems. Among the measurement platforms desired are the National Center for Atmospheric Research Electra aircraft with DIALs and the mini-MOPA (Master Oscillator Power Amplifier). As a result of a planning meeting held on April 1, 1999, IHOP was delayed from spring 2000 to spring 2001.

SCM IOP (Spring 2001). This SCM IOP would support operations of the IHOP/TIMEx Campaign. 


\section{REFERENCES}

McPherson, R.A., and K.C. Crawford, 1996, "The EARTHSTORM Project: Encouraging the Use of Real-Time Data from the Oklahoma Mesonet in K-12 Classrooms," Bulletin of the American Meteorological Society 77:749-761.

Melvin, A.D., and R.A. McPherson, 1998, "Southern Great Plains Atmospheric Radiation Measurement (ARM) Educational Outreach Program," in Preprints, Seventh Symposium on

Education, January 11-16, 1998, Phoenix, Arizona, American Meteorological Society, Boston, pp. 23-26.

Peppler, R.A., and M.E. Splitt, 1998, "ARM Southern Great Plains CART Site Data Quality Assessment Activities," in Preprints, 10th Symposium on Meteorological Observations and Instrumentation, January 11-16, 1998, Phoenix, Arizona, American Meteorological Society, Boston, pp. 355-358.

Peppler, R.A., D.L. Sisterson, and P. Lamb, 1999, Site Scientific Mission Plan for the Southern Great Plains CART Site, January-June 1999, ARM-99-001, U.S. Department of Energy, Washington, D.C., January.

U.S. Department of Energy, 1990, ARM Program Plan, 1990, DOE/ER-0441, Washington, D.C.

U.S. Department of Energy, 1996, Science Plan for the Atmospheric Radiation Measurement Program, DOE/ER-0670T, Washington, D.C. 